\title{
TRANSIENT AXIAL THRUST OF HIGH-HEAD PUMP- TURBINE AT LOAD REJECTION
}

\author{
Junichi KUROKAWA, \\ Yokohama National University, \\ Yokohama, Japan \\ Morihito INAGAKI, \\ Tokyo Power Electric Co. Ltd., \\ Tokyo, Japan \\ Hiroshi IMAMURA, \\ Yokohama National University, \\ Yokohama, Japan \\ Tadashi TAGUCHI, \\ Tokyo Power Electric Co. Ltd., \\ Tokyo, Japan \\ Kazuo NIIKURA \\ Hitachi Co. Lid., \\ Hitachi, Japan
}

\begin{abstract}
In the load rejection test of Kazunogawa pumped storage P. S. in Japan, an abnornal axial thrust occurred in a high-head reversible pump-turbine ( $412 \mathrm{MW}$ and $714 \mathrm{~m}$ effective head). The rotating parts including a runner moved $4 \mathrm{~mm}$ upward in the axial direction. After taking several countermeasures, this machine is now operating without any problem, but the detailed mechanism of transient axial thrust is not yet clear, though such a transient up-thrust has long been known.

The present study is thus aimed to determine the reason why such abriomal axial thrust is caused at the transient operation and how to reduce abnormal thrust. Here adopted is a theoretical approach which has been proved to give satisfactory results in predicting pump axial thrust.

\section{RÉSUMÉ}

Lors des tests de coupure de la centrale à acciunulation de Kazunogawa au Japon, une poussée axiale anormale est apparue dans une pompe-turbine haute chute ( $412 \mathrm{MW}$ et $714 \mathrm{~m}$ de chute effective). Les parties en rotation, y compris la roue, se sont soulevées axialement de $4 \mathrm{~mm}$. Après avoir entrepris plusieurs mesures correctives cette machine fonctionne maintenant normalement. Toutefois le mécanisme détaillé conduisant à cette poussée axiale transitoire vers le haut n'est pas encore clair, bien que ce phénomène soit connu depuis longtemps.

La présente étude a ainsi pour but de déterminer les raisons pour lesquelles cette poussée axiale est apparue lors des manouvres transitoires et comment la réduire. Une approche théorique ayant montré des résultats satisfaisant pour la prédiction de poussée axiale dans les pompes a été utilisée.
\end{abstract}

\section{NOMENCLATURE}

\begin{tabular}{|l|l|l|}
\hline Term & Symbol & Definition \\
\hline $\begin{array}{l}\text { Leakage flowrate } \\
\text { coeff. }\end{array}$ & $\mathrm{C}_{\mathrm{q}}$ & $\mathrm{Q}_{1} / 2 \pi \mathrm{r}_{0}^{3}()$ \\
\hline Axial force coeff. & $\mathrm{C}_{\mathrm{T}}$ & $2 \mathrm{~T} / \rho \mathrm{r}_{0}^{4} \omega^{2}$ \\
\hline $\begin{array}{l}\text { Tangential velocity } \\
\text { ratio }\end{array}$ & $\mathrm{K}$ & $\mathrm{U} / \mathrm{r}(1)$ \\
\hline
\end{tabular}

\begin{tabular}{|l|l|l|}
\hline Term & Symbol & Definition \\
\hline Radius & $\mathrm{r}$ & $\mathrm{r}_{0}$ : runner radius \\
\hline Radius ratio & $\mathrm{R}$ & $\mathrm{r} / \mathrm{r}_{0}$ \\
\hline Reynolds number & $\mathrm{Re}$ & $\mathrm{r}_{0}{ }^{2}(0) / v$ \\
\hline
\end{tabular}




\begin{tabular}{|l|l|l|}
\hline Term & Symbol & Definition \\
\hline Leakage flowrate & $\mathrm{Q}_{1}$ & \\
\hline Axial thrust coeff. & $\Delta \mathrm{C}_{\mathrm{T}}$ & $2 \mathrm{AT} / \rho \pi \mathrm{r}_{0}{ }^{4} \omega^{2}$ \\
\hline Azial thrust & $\Delta \mathrm{T}$ & $\begin{array}{l}\mathrm{T}_{\mathrm{C}}-\mathrm{T}_{\mathrm{B}} \\
-\rho \mathrm{QV}-\mathrm{F}_{\mathrm{B}}\end{array}$ \\
\hline Subscript & $\mathrm{C} \& \mathrm{~B}$ & Crown \& Band \\
\hline
\end{tabular}

\begin{tabular}{|l|l|l|}
\hline Term & Symbol & Definition \\
\hline Axial force & $\mathrm{T}$ & \\
\hline Fluid density & $\rho$ & \\
\hline Subscript & $\mathrm{BH}$ & Balancing hole \\
\hline Subscript & $\mathrm{BP}$ & Balancing pipe \\
\hline
\end{tabular}

\section{INTRODUCTION}

In the load rejection test of Kazunogawa pumped storage P. S. in Japan, an abnormal axial thrust occurred in the No. 1 reversible pump-turbine (vertical axis Fransis type, 412MW and $714 \mathrm{~m}$ effective head). The rotating parts including a runner moved $4 \mathrm{~mm}$ upward in the axial direction. After taking several countermeasures, this machine is now operating without any problem, but the detailed mechanism of transient axial thrust is not yet clear.

The aim of the present study thus is ; 1) to make clear the mechanism of so-called "up-thrust" in the transient operation of a high-head pump-turbine, 2) to establish the prediction method of axial thrust, 3) to propose the method of reducing such an abnormal axial thrust.

Axial thrust of high-head pump turbine amounts to only $1 \%$ or less of the fluid force acting on one back wall of a runner, and the Reynolds number amounts to more than $10^{8}$. Therefore, an accurate prediction is still very difficult due to such a small axial thrust and a large Reynolds number, even if the state of the art CFD codes are applied to axial thrust prediction. In addition, there are still many problems in the steady axial thrust, such as a scale effect of axial thrust, an increase of axial thrust due to wear of seal parts, and so on. Thus one more aim of the present study is 4) to determine the scale effect of axial thrust.

Authors have long been developing a theoretical method of predicting axial thrust of pumps. This method has been proved to give satisfactory results for the prediction of pump thrust (Refs. 1,2). In the present paper, a theoretical approach is taken to predict the behavior of steady and transient axial thrust, and the results are compared with the experimental data.

\section{THEORY AND CALCULATION PROCEDURE}

\section{Theory}

Axial thrust is a residual force of all the fluid forces acting on runner surface. The main part of axial thrust is the difference of both axial forces acting on the back of crown and band of a runner. These axial forces are remarkably influenced by leakage. In both back sides of a runner many balancing devices are adopted to reduce axial thrust, such as balancing pipes and balancing holes. As the balancing devices form many leakage paths, the accuracy of axial thrust calculation is largely dependent upon the leakage calculation in a practical use.

Therefore, in order to determine the axial forces in the range of very large Reynolds number, it is necessary to adopt integral method using the universal velocity law, that is logarithmic velocity distribution. One of the present authors has developed this theory to reveal the roughness effect of rotating disk flow (Ref. 3). Here, it is further developed to determine the axial thrust behavior in the very large Reynolds number range of a high-head runner equipped with many kinds of balancing devices.

The flow at the back of a runner is basically analyzed using a rotating disk flow enclosed in a cylindrical casing, in which the governing equations are expressed as follows: 
Equation of Continuity

Angular Momentum Balance

Momentum Balance

$$
\begin{aligned}
& \int_{0}^{\theta} v d z+\int_{0}^{\delta} v^{\prime} d z^{\prime}=Q_{l} / 2 \pi r \\
& \frac{\partial}{\partial r}\left\{\int_{0}^{g} r^{2} u v d z+\int_{0}^{\delta} r^{2} u^{\prime} v^{\prime} d z^{\prime}\right\}=-\frac{r^{2}}{\rho}\left(\tau_{R \theta}+\tau_{S \theta}\right) \\
& \frac{\partial p}{\partial r}=\rho \frac{v^{2}}{r}
\end{aligned}
$$

where $\mathrm{z}$ is the axial distance from wall and $\mathrm{r}$ is radius. $u$ and $v$ are tangential and radial velocities, respectively and prime(") refers to rotating wall. $p$ and $\tau$ are pressure and shearing stress (Subscripts $\theta$ denotes tangential component) and $\vartheta, \delta$ are boundary layer thickness along the stationary $(S)$ and rotating $(R)$ wall, respectively. $Q_{l}$ is the leakage flow-rate.

For velocity profile, logarithmic velocity applicable to high Reynolds number is assumed ;

$$
\begin{aligned}
& u / v_{*}=\phi(\eta), v / v_{*}=-a\left(1-\eta / \eta_{1}\right) \phi(\eta) \\
& u^{\prime} / v^{\prime}=r \omega / v^{\prime}-\phi(\zeta), v^{\prime} / v_{*}^{\prime}=a^{\prime}\left(1-\zeta / \zeta_{1}\right) \phi(\zeta)
\end{aligned}
$$

where, $\phi(\xi)=2.5 \ln (9 \xi+1), \xi=v_{* z} / v$, and subscript 1 refers to the edge of boundary layer. The friction velocity $v_{*} \equiv \sqrt{\tau_{S} / \rho}, v^{\prime} \equiv \sqrt{\tau_{R} / \rho}$ are determined from the boundary condition;

$$
u=u^{\prime}=K r \omega \quad \text { at } \quad z^{\prime}=\vartheta\left(\eta=\eta_{1}\right), z=\delta\left(\zeta=\zeta_{1}\right)
$$

The boundary layer thickness on the rotating wall is assumed referring to Daily (Ref-4) as

$$
\delta=0.526(1-K)^{2} r /\left(\omega r^{2} / v\right)^{\frac{1}{5}}
$$

Substituting Eqs.(4) (7) to Eqs.(2) and (3) through Eq.(1), two ordinary differential equations as for the tangential velocity ratio $K \equiv U / r \omega$ and the non-dimensional pressure $C_{p} \equiv 2 p / \rho r_{0}^{2} \omega^{2}$ are expressed as a f unction of radius ratio $R \equiv r / r_{0}$.

To solve these equations in a high-head pump turbine, it is of key importance to determine accurate boundary values, which are given by solving the following equation of the angular momentum balance at every control surface where the space configuration changes.

$$
\int_{r_{i}}^{r_{i}+\Delta r} 2 \pi r^{2}\left(\tau_{R \theta}-\tau_{S \theta}\right) d r+M_{C R}-M_{C S}=A M_{\text {out }}-A M_{\text {in }}
$$

where, $A M_{\text {out }}, A M_{\text {in }}$ are angular momentum which leakage takes into or brings out of the control surface, and $M_{R C}, M_{S C}$ are friction torque of rotating and stationary cylindrical wall.

\section{Runner Configuration Analyzed and Transient Up-Thrust}

The configuration of Kazunogawa No.1 runner is shown in Fig. 1 together with several balancing devices, the outer balancing pipes (BP) connecting the backs spaces between band and crown, the inner balancing pipes ( $\mathrm{BP}_{\mathrm{DT}}$ ) connecting crown to draft tube, and balancing holes $(\mathrm{BH})$. The leakage paths are also illustrated in the figure, in which the non-dimensional leakage $C_{q C}, C_{q B}$ at the inlet of crown and band, $C_{q E P}, C_{q D T}$ at the outer and inner balancing pipes, respectively, and $C_{q B H I}$ at the balancing hole. 


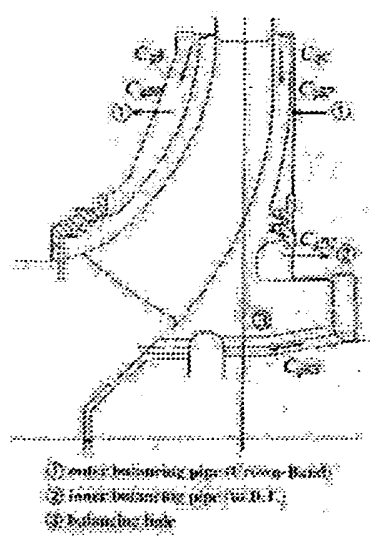

Fig. 1 No.1-Runner

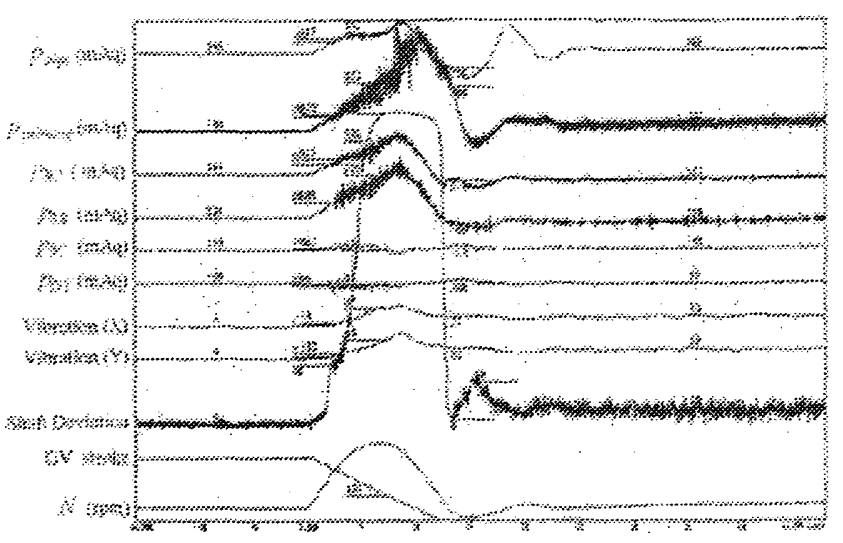

Fig. 2 Time history of load rejection test $-3 / 4$ Load

Assuming every leakage adequately, the pressure distribution around a runner is calculated, and then every leakage is so modified that all the boundary pressures at the outlet of all flow fields (BP outlet, $\mathrm{BP}$ DT outlet, $\mathrm{BH}$ outlet) are equal to the given values. Axial thrust $\Delta T$ is given as the difference of axial forces $T_{C}$ at the back of crown and $T_{B}$ at the back of band including the momentum change $\rho Q V$ of outlet flow; $\triangle T=T_{C}-T_{B}-\rho Q V-F_{B}$, where, $F_{B}$ is the axial force caused by the downstream pressure at the nunner outlet.

The measured time history of the load rejection test is illustrated in Fig. 2, in which a large up-thrust is seen at about $3 \mathrm{~s}$ after the start. This also reveals that an abnormal phenomena, such as water hammering or draft surge, is not the cause of the present up-thrust.

\section{RESULTS AND DISCUSSIONS (1) ----- TRANSIENT AXIAL THRUST}

To reveal the cause of up-thrust, the following items should be fully examined;

(1) Flow unsteadiness, or a time lag due of the response to the sudden increase of rotational speed and pressure in the runner backside flow

(2) Peculiar behaviors of runner inlet flow and outlet flow (flow in the runner eye)

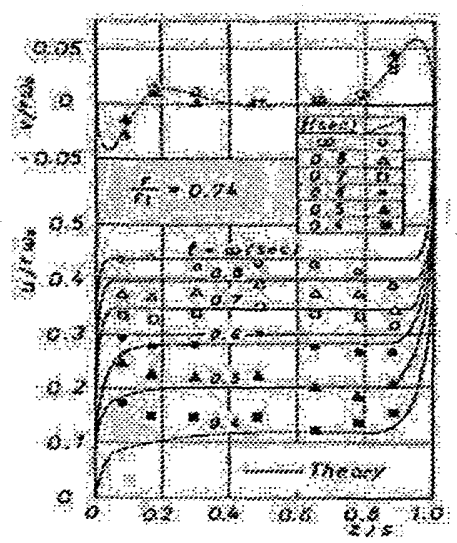

(a) Tangential velocity

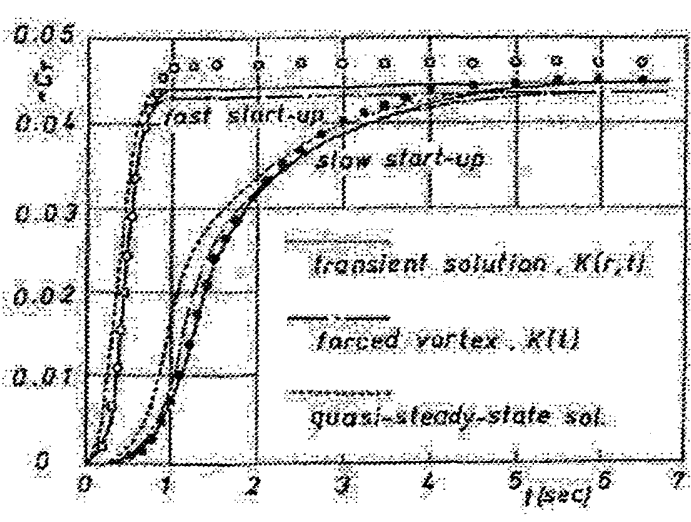

(b) Axial force

Fig. 3 Unsteadiness of flow along an enclosed rotating disk at the start-up 


\section{Flow Unsteadiness}

The unsteadiness of the rotational flow is caused by acceleration or deceleration of the wall speed, and can be basically studied referring to the flow along a suddenly accelerated rotating disk. One of the present authors (Ref. 5) revealed that the velocity field along an enclosed rotating disk is formed very fast following the change of disk rotational speed as shown in Figs. 3 (a) and (b).

When the disk starts to rotate in an infinite space, the disk boundary layer is formed very slowly due to fluid viscosity. But in the case of enclosed rotating disk in a cylindrical casing, the fluid starts to rotate very quickly with the time lag of $0.3 \mathrm{~s}$ because of the secondary flow effect (Ref. 5). The velocity field is formed very quickly as shown in Fig. 3(a), and the axial force also follows the rotational speed very quickly as shown in Fig. 3(b).

Compared with the above-mentioned change, Fig. 2 reveals that the phenomena is much slower in the load rejection of a pump-turbine, and then it is concluded that the flow-field at the back of a runner can be treated as quasi-steady. Here, the change of pressure in the outer radii might cause appreciable time lag to the flow change in the inner radii due to the fluid viscosity in the annular seal. According to Ref. 6 of a suddenly accelerated pipe flow, the velocity field is formed very quickly with the time lag of about $0.8 \mathrm{~s}$ following the pressure change. This result suggests that the velocity field of a seal flow is also formed very quickly.

To show the seal effect of a high head pump-turbine, the calculated pressure distribution is shown in Fig. 4 with the comparison with the measurements of the model test. The annular seal is so tight that about a half of the runner head drops at the step-type annular seal. Further calculation revealed that the runner seal is so tight that the pressure changes little in the inner radii in spite of large pressure change in the outer radii. This also means that a large pressure change in the outer radii causes so large change of leakage flow-rate as to keep the pressure in the inner radii almost constant.

From these results, it is concluded that the runner backside flow responds so quickly to the change of runner inlet pressure and rotational speed that it can be treated as quasi-steady. In the following calculations the transient axial thrust is treated as quasi-steady state.

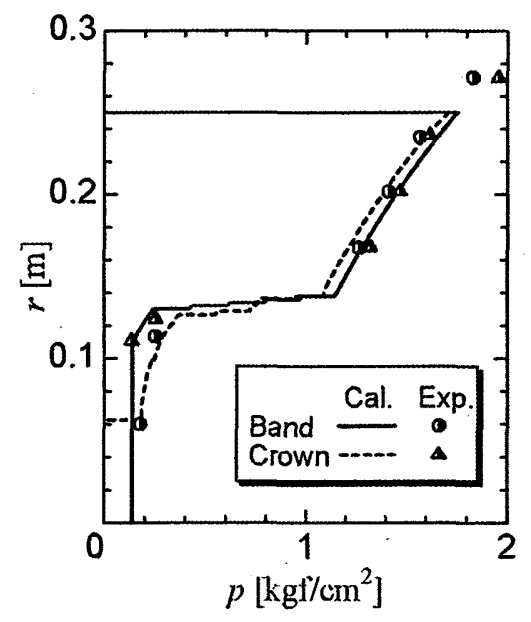

Fig. 4 Pressure distribution at the back of runner 


\section{Peculiar Behavior of Runner Inlet Flow and Outlet Flow}

To reveal the cause of up-thrust at the load rejection, the transient axial thrust is calculated using the measured pressures at runner inlet and draft tube inlet as the boundary values.

The calculated time history of axial thrust is shown in Fig. 5(a), in which the runner inlet pressures $p_{I C,}, p_{I B}$ at the crown and band are estimated under the assumption that they are proportional to the priming pressure in Fig. 2. This result reveals that there is no possibility of abnormal up-thrust at the load rejection in spite of large change of $p_{I C,} p_{I B}$.

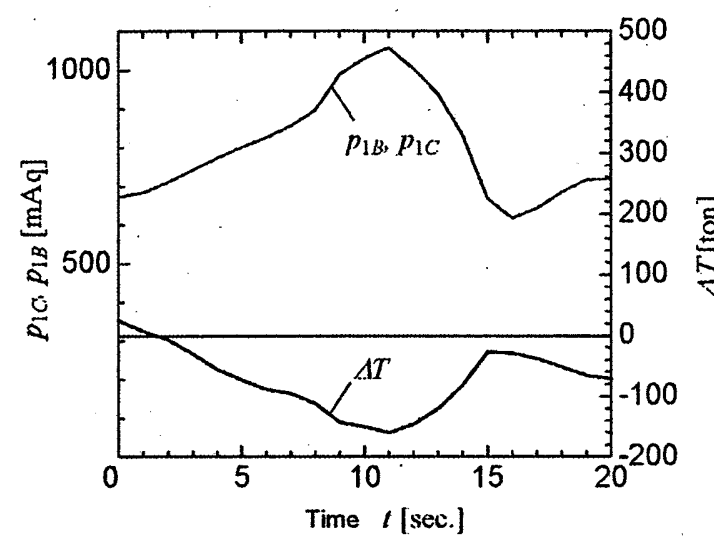

(a) Assuming $p_{1 C}, p_{1 B} \propto p_{\text {priming }}$

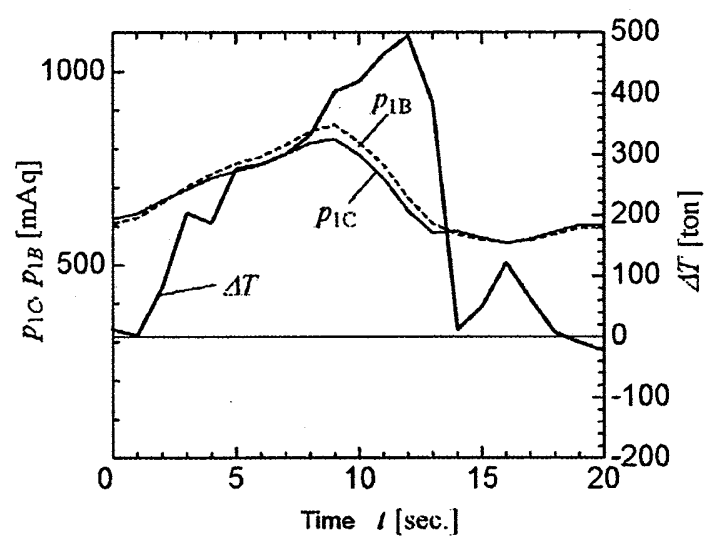

(b) Assuming $\left(p_{3 c}, p_{3 B}\right)_{c a l c .}=\left(p_{3 c}, p_{3 B}\right)_{\text {meas. }}$

Fig. 5 Calculated time history of axial thrust under different assumptions

In the load rejection the runner outlet flow changes and has a strong swirl which causes a rapid pressure drop around a runner cone. To reveal this effect on axial thrust, calculations were further performed changing the runner outlet condition. The extreme case is that the runner cone pressure is zero, in which case the upward axial thrust increased a little. It is thus revealed that the runner outlet flow behavior has no possibility of causing any abnormal axial thrust even if it is extremely different from the normal state.

Here, it is to be paid attention in Fig. 2 that the measured back pressures at $\mathrm{R}=0.81$ have small difference between band and crown by about $1 \sim 2 \%$ throughout the load rejection, though the calculation gave no difference. This difference should come from the difference of the flow at the runner inlet.

In order to confirm this influence on axial thrust, the runner inlet pressures $p_{I C}, p_{I B}$ were so modified that the both calculated pressures at the measuring points are equal to the measured. The calculated time history of axial thrust is shown in Fig. 5(b). It reveals that the maximum up-thrust of 495 ton is calculated, which is nearly equal to the weight of rotating part. Moreover, the configuration of time dependence curve of axial thrust is very near to the measured, and the calculated period of the maximum up-thrust is same as the measured. This reveals that the cause of abnormal up-thrust is the pressure difference between band and crown at the runner periphery. In Fig. $5(\mathrm{~b})$ is also plotted the runner inlet pressures $p_{I C}, p_{I B}$, which take the maximum at $3 \mathrm{~s}$ faster than the period of maximum-thrust and $2 \mathrm{~s}$ slower than the period of maximum rotation. This also reveals that the sudden increase of priming pressure and rotational speed due to guide vane closure is not the direct origin causing abnormal axial thrust.

If the pressure difference at runner inlet were $1 \%$ higher in the band and $1 \%$ lower in the crown, the calculated up-thrust could be 630 ton, which exceed the weight of rotating parts. 


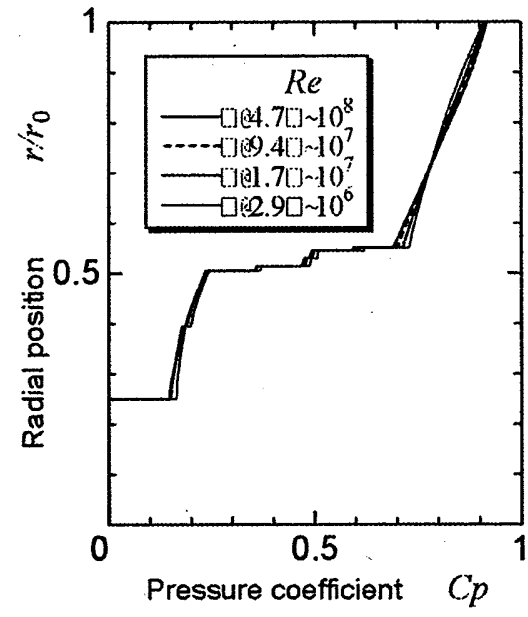

(a) Radial pressure distribution

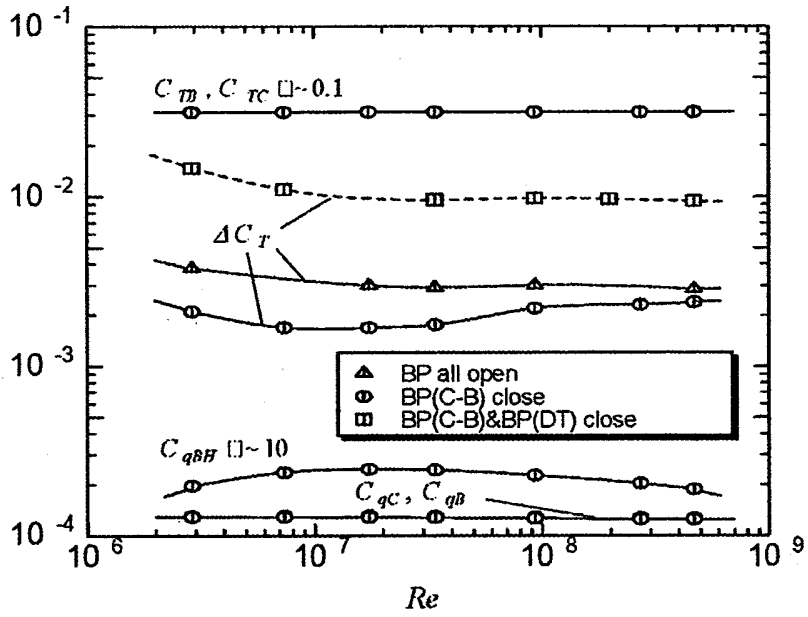

(b) Leakage, axial force and caxial thrust

Fig. 6 Scare effect -Influence of the Reynolds number

Cause and Countermeasure of Up-Thrust

As discussed in the above, the main cause of abnormal up-thrust should be the pressure difference in the runner inlet section between crown and band, and the abnormal flow in the runner outlet section should not cause such large up-thrust. Transient flow behavior at the back of a runner also should not cause abnormal axial thrust. The calculation also reveals that the difference of runner inlet pressure between crown and band exists not only in the transient operation but in the steady operation as shown at the period of $t=0 \mathrm{~s}$ in Fig. 5(b). The problem is that this pressure difference becomes larger in the transient operation due to a sudden decrease of How-rate. In pumps the outlet flow from a centrifugal impeller deviates to suction side and has the same kind of pressure difference in the low flow operation, which cause a rapid increase of axial thrust.

When the balancing pipes are mounted between crown and band, the axial thrust curve in Fig. 5(b) moves almost parallel to the downward direction, resulting in that the maximum axial thrust becomes much smaller. When the balancing pipes are mounted near to the runner periphery, the axial thrust almost balances.

\section{RESULTS AND DISCUSSIONS (2) -...- SCALE EFFECT IN AXIAL THRUST}

Axial thrust of a prototype is usually estimated from the model test under the assumption of similarity law. However, axial thrust is remarkably influenced by leakage, which is largely dependent on seal gap friction. Axial thrust thus should be influenced by the Reynolds number. The calculated pressure distribution at the back of crown is compared for the variation of the Reynolds number in Fig. 6(a). The non-dimensional pressure is seen almost same regardless of the Reynolds number. In this case the non-dimensional leakages $C_{q c}, C_{q b}$ and $C_{q D T}$ was also almost same regardless of the Reynolds number but for $C_{q B H}$.

To show this more clearly, the non-dimensional values of leakage, fluid force and axial thrust are shown against the Reynolds number in Fig. 6(b). It is clearly shown that the similarity law is valid in the leakage $C_{q C}, C_{q B}$ and in the axial force $C_{T C} . C_{T B}$ in the crown and band, respectively. However the non-dimensional axial thrust $\Delta C_{T}$ varies depending on the Reynolds number, which is because of the change of the balancing hole leakage $C_{q B I I}$. As the axial thrust amounts only to $0.5 \%$ (outer BP close) $3 \%$ (outer \& inner BP close) of the fluid 
force working on one wall, a small change of leakage influences the balance of the fluid force, resulting in a complicated behavior of axial thrust curve against the Reynolds number. It is then concluded that the axial thrust should not be estimated from model test.

\section{CONCLUSION}

From the present calculations, some remarkable results were obtained as follows;

(1) The main cause of abnormal up-thrust at the load rejection is not essentially the increase of effective head and rotational speed or a swirl flow at the runner outlet, but the pressure difference at a runner inlet between band and crown. At load rejection, since the flow rate doesn't follow the runner speed, the runner flow comes into a low flow condition. The runner inlet flow might be inclined to crown side, which causes low velocity region at band side and makes the pressure at band side higher than that at crown side.

(2) Estimating the leakage flow rate in each part with high accuracy, the predicted axial thrust is in good agreement with the measured. From the review of past studies, it is concluded that the transient phenomena at load rejection can be treated as quasi-steady.

(3) Large axial thrust can remarkably be reduced in the steady or transient operation by using balancing pipes between crown side and band side at outer radii.

(4) Similarity law is valid both in axial forces at the back of runner and in leakage at the outer radii. However, similarity law is not valid for axial thrust due to the dependence of balancing hole leakage on the Reynolds number, though the dependence is not large.

\section{REFERENCES}

Ref. 1 Kurokawa, J. \& Toyokura, T. , 1976, "Axial Thrust, Disk Friction Torque and I.eakage Loss of Radial Flow Turbomachinery", Proc. Pumps and Turbines Conf. (Glasgow), Vol. 1, 1976-9, 8 pages.

Ref. 2 Kurokawa, J., Kamijyo, K. \& Shimura, T, 1994, "Axial Thrust Behavior in LOX-Pump of Rocket Engine", AIAA Journal of Propulsion and Power, Vol. 10, No. 2, 1994, pp. 244-250.

Ref. 3 Kurokawa, J., Toyokura, T., Shinjo, M. \& Matsuo, K., 1978, "Roughness Effects on the Flow along an Fnclosed Rotating Disk, Bull. JSME, Vol. 21, No. 162, 1978, pp. 1725-1731.

Ref. 4 Daily. J. W. \& Nece, R.E., 1960, "Chamber Dimension Effects on Frictional Resistance of Enclosed Rrotating Discs", Trans ASME, Ser.D, Vol. 82, No.3, 1960, pp. 553-559.

Ref. 5 Kurokawa, J., Toyokura, T., Ishiwata, R. \& Sugiura, M., 1981, "Transient Flow Caused by a Rotationally Decelerated Disk Enclosed in a Housing", Bull. JSME, Vol.24, No.195, 1981, pp.15721578.

Ref. 6 Kurokawa, J. \& Morikawa, M., "Accelerated and Decelerated Flows in a Circular Pipe", Bull. JSME, Vol. 29, No. 249 (1986(.13), pp. 758-764. 